\title{
Risk of malignant lymphoma in Swedish agricultural and forestry workers
}

\author{
KERSTIN WIKLUND, BRITT-MARIE LINDEFORS, L-E HOLM \\ From the Departments of Cancer Epidemiology and General Oncology, Radiumhemmet, Karolinska Hospital \\ and Institute, S-104 01 Stockholm, Sweden
}

\begin{abstract}
The risk of malignant lymphoma after possible exposure to phenoxy acid herbicides was studied in 354620 Swedish men who, according to a national census in 1960, were employed in agriculture or forestry. The cohort was divided into subcohorts according to assumed exposure and compared with 1725645 Swedish men having other economic activities. All were followed up in the Cancer-Environment Register between 1961 and 1979. Non-Hodgkin lymphoma was found in 861 men in the study cohort. The relative risk was not significantly increased in any subcohort, did not differ significantly between the subcohorts, and showed no time related increase in the total cohort or any subcohort. Hodgkin's disease was found in $\mathbf{3 5 5}$ men in the study cohort. Relative risks significantly higher than unity were found among fur farming and silviculture workers where the relative risks were 4.45 and $2 \cdot 26$, respectively. All five cases in the former group were engaged in mink farming. A time related rising trend in relative risk was found in the silviculture subcohort. Elsewhere the relative risk did not diverge from unity and no time related trend was discernible.
\end{abstract}

Exposure to phenoxy acid herbicides or chlorophenols have been associated with a subsequent increased risk of Hodgkin's disease (HD) or of nonHodgkin lymphoma (NHL), or both. ${ }^{1-5}$ The increased risk has been found in, for example, Vietnam veterans exposed to Agent Orange and workers in a British plant making pentachlorophenols. In a recent study Hoar et al found farm herbicide use to be associated with NHL but not with HD. ${ }^{5}$ They also found a sixfold increased risk of NHL in men exposed to herbicides for more than $\mathbf{2 0}$ days a year. According to Hardell "The mechanism of the relationship is unclear, though a conceivable mode of action may be immunological depression, which is described for dioxins, especially TCDD, or mutagenic effects by phenoxy acids, which were demonstrated in some test systems (Seiler)."1 Several other studies, however, have failed to observe any such relation. ${ }^{6-10} \mathrm{An}$ excess of total cancer mortality has been observed in some groups of workers exposed to phenoxy acid $^{11-14}$ but not in other groups. ${ }^{15-23}$

Most occupational handling of phenoxy acid herbicides in Sweden occurs in agriculture or forestry. A

Accepted 1 December 1986 study of cancer morbidity among Swedish agricultural workers in 1961-73, based on the Swedish cancer-environment register (CER), found no increased risk of malignant lymphoma. ${ }^{24}$ The CER has since then been supplemented with malignant tumours notified between 1974 and 1979 and now comprises all cases of cancer diagnosed in Sweden in 1961-79. This allows the study of large cohorts over long periods, which in turn provides opportunities for the analysis of time trends.

The aim of the present study was to analyse the time related trend in the risk of malignant lymphoma not only in Swedish agricultural but also in horticultural and forestry workers due to the greatly increased use of phenoxy acids over the past decades. ${ }^{25}$

\section{Material and methods}

The studied cohort consisted of 354620 Swedish men born between 1891 and 1940 who stated that they were employed in agriculture or forestry in a nation wide population and housing census in 1960 (PH 60). To obtain groups with presumably more homogeneous exposure to phenoxy acids, the cohort was divided into six subcohorts. The reference cohort 
comprised 1725845 Swedish men of the same age and employed in other economic activities than agriculture or forestry according to $\mathrm{PH} 60$. Table 1 shows the number of men and person-years of follow up.

The cohorts were defined by economic activity (industry) instead of by occupation, since a previous study ${ }^{26}$ had shown that the coding of economic activity was better than that of occupation in PH 60 .

The assumed exposure to chemical herbicides in the various subcohorts was based on figures for estimated sales of phenoxy acids ${ }^{25}$ and estimated use of different herbicides in agriculture, forestry, and horticulture (D Johansson, personal communication). The assumptions are therefore only rough estimates of true exposure. No information on active or passive individual exposure was available. In a postal survey concerning the use of pesticides in the studied cohort during the 1950s, 1960s, and 1970s, however, at least $25 \%$ stated that they had used phenoxy acid herbicides one day or more during that period. The use of protective equipment has been very sporadic, particularly during the 1950s and the 1960s (J Dich, personal communication).

The phenoxy acid compound predominantly used in Swedish agriculture is 4-chloro-2-methylphenoxyacetic acid (MCPA). The two compounds 2,4-dichlorophenoxyacetic acid (2,4-D) and 2,4,5-trichlorophenoxyacetic acid (2,4,5-T) and some of their esters have also been used, although to a lesser extent than MCPA. ${ }^{24}$ In Swedish forestry the herbicide mainly used since the early $1950 \mathrm{~s}$ is $2,4,5-\mathrm{T}$, but 2,4-D has also been used.

The six subcohorts and their presumed exposure to phenoxy acid or other herbicides were as follows.

1 Land/animal husbandry-This group comprised owners and tenant farmers and also men who stated that they had farming occupations even with industrial employers. The subcohort was assumed to have been exposed mainly to MCPA and to some extent also to 2,4-D or 2,4,5-T, or both.

2 Horticulture-All men who stated that they worked in market gardens were included in this group but not those who tended parks or cemeteries. The

Table 1 Number of men and person-years of follow up in agricultural and forestry workers and in the reference cohort

\begin{tabular}{lrc}
\hline & $\begin{array}{l}\text { Men in } \\
\text { census } \\
\text { (1960) }\end{array}$ & $\begin{array}{l}\text { Person-years } \\
\text { of follow up } \\
\text { (1961-79) }\end{array}$ \\
\hline Agriculture/forestry (total): & 354620 & 6070769 \\
Land/animal husbandry & 254417 & 4330717 \\
Horticulture & 11626 & 199281 \\
Other agricultural occupations & 14126 & 243781 \\
Silviculture & 7215 & 126624 \\
Timber cutting & 61153 & 1066316 \\
Other forestry occupations & 6083 & 104050 \\
Reference cohort & 1725845 & 30131674 \\
\hline
\end{tabular}

subcohort was assumed to have been exposed to other herbicides than phenoxy acids.

3 Other agricultural occupations-Reindeer husbandry, fur farming, or miscellaneous occupations in farm or horticultural work and care of animals other than livestock constituted this group. The men's exposure to herbicides was assumed to have been heterogeneous.

4 Silviculture-These men reported that they were engaged in planting, thinning, or other duties in the care and maintenance of forests. They had presumably been exposed to 2,4,5-T and to some extent also to 2,4-D.

5 Timber cutting-Felling and trimming of trees and transportation of timber were the occupations in this group. The men were considered to have been passively exposed to 2,4,5-T and 2,4-D in connection with their work.

6 Other forestry occupations-Rafting of timber, timber scaling, hunting, game keeping, or other, imprecisely defined forestry work were all assigned to this group. The exposure to phenoxy acid or other herbicides, or both, was assumed to be heterogeneous.

Phenoxy acids contain the contaminants polychlorinated dibenzo-para-dioxins (PCDDs). Only 2,4,5-T, among the phenoxy acids, is considered to be contaminated with 2,3,7,8-tetrachloro-dibenzoparadioxin (TCDD), which is the most toxic dioxin isomer. Other phenoxy acids are contaminated with dioxins that are less toxic than TCDD. The forestry subcohorts 4-6 were therefore assumed to have been more exposed to TCDD than the agricultural subcohorts $1-3$.

Although the purpose of division into subcohorts was to obtain groups with relatively homogenous herbicide exposure, a relevant point is that in Sweden many agricultural workers periodically do forestry work and vice versa. Thus even within the subcohorts there was heterogeneity in such exposure. The men of the study cohort, however, may be assumed to have been exposed to phenoxy acids to a greater extent than men whose contact with these substances was limited to leisure time.

FOLLOW UP OF THE COHORTS

All cases of malignant lymphoma were identified in the CER. The tumors included were HD and NHL according to international classification of diseases, 7 th revision. ${ }^{27}$

CER was established by a computerised record linkage between the nationwide cancer register and PH 60; it contains all cancer register data of primary tumours notified between 1961 and 1979. These data include the unique personal identity number given to all residents in Sweden (which includes date of birth), site and histological type of tumour, basis for and 
date of diagnosis, and date of death and underlying and contributory causes of death. These data derive from the obligatory notifications of cases of cancer by clinicians and pathologists and from death certificates. The data supplied by PH 60 to the CER concerned occupation, economic activity (industry), and domicile in 1960. The constitution and deficiencies of CER have been discussed elsewhere. ${ }^{28}$

The numbers of person-years of observation in the total study cohort, the subcohorts, and the reference group were calculated from 1 January 1961 until 31 December 1979 or until death before the closing date. Each fatal case was calculated to have contributed half a person-year for the year of death.

Relative risk estimates (RR) (Mantel-Haenszel incidence density ratio) were calculated for the cohorts versus the reference group, with adjustment of potential confounding variables by stratification. ${ }^{29}$ Stratification variables were year of birth in five year classes and domicile in 1960 (county or the cities of Stockholm, Gothenburg, and Malmö). The cases of malignant lymphoma were grouped in three periods according to year of diagnosis: $1961-6,1967-73$, and 1974-9.

Age standardised incidence of malignant lymphoma per 100000 of the total Swedish male population between 1961 and 1979 was obtained from the Swedish Cancer Registry. These data together with RR and numbers of cases in the respective cohorts were used to estimate the age standardised incidence per 100000 in the study and the reference cohorts in the three periods studied.

The size of the subcohorts varied widely and the standard errors and the confidence intervals (CI) for RR were therefore calculated according to different principles. Standard errors and CI were calculated according to Breslow ${ }^{30}$ for the total study cohort (agriculture and forestry) and the largest subcohort (land/animal husbandry). The confidence limits for RR in the other subcohorts were calculated with a Poisson distribution table. These subcohorts were considerably smaller than the reference group, in which the standard error was regarded as negligible.

Trends in RR for the three periods of study were tested according to Breslow and Day. ${ }^{31}$ The hypothesis of homogeneity in RR against heterogeneity between subcohorts was tested according to Breslow and Day. ${ }^{31}$

\section{Results}

Between 1961 and 1979 a total of 1216 malignant lymphoma was reported in the study cohort and 4929 in the reference cohort. The number of cases of NHL in the study cohort was 861 versus 3500 in the reference cohort. No RR in the subcohorts differed significantly from unity (table 2 ). Moreover, the subgroups did not differ significantly as regards $R R$, and tests of trend showed no time related change in RR in any subcohort (table 2). The age standardised incidence of NHL increased both in the total study cohort and in the reference cohort.

The total number of cases of HD in the study cohort was 355 and 1429 in the reference cohort. RR significantly greater than unity was found in the subcohorts other agricultural occupations and silviculture (table 3 ). A statistically significant increase in RR with time was also found in these subcohorts (table 3). In the other subcohorts RR did not differ significantly from unity and no time related trend was detectable (table 3 ). The age standardised incidence of HD was about the same in periods 1 and 3 in the study cohort, whereas in the reference cohort a decrease over time was discernible.

The subcohort other agricultural occupations was miscellaneous and was therefore divided at the lowest classification level-that is, according to the three digit code for economic activity used in PH 60. The result of this analysis is summarised in table 4. Only in fur farming was the RR found to be statistically higher than unity.

The hospital records, PH 60 forms, and records from population registers of the people in the subcohorts with tendency to excess risk for HD were reviewed-namely, the 15 silviculture workers (table 3 ), the five men engaged in fur farming, the four men in animal care other than stock husbandry, and the 12 men in other relevant occupations (table 4). The aim

Table 2 Observed number of cases of non-Hodgkin lymphoma in 1961-79, relative risks and 95\% confidence intervals for the total period, and relative risks for the three periods

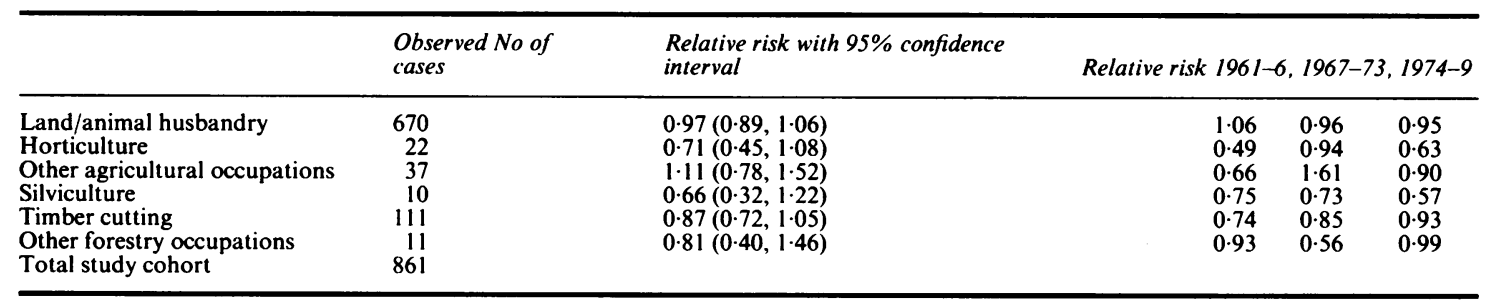


Table 3 Observed number of cases of Hodgkin's disease in 1961-79, relative risks and 95\% confidence intervals for the total period, and relative risks for the three periods

\begin{tabular}{|c|c|c|c|c|c|}
\hline & $\begin{array}{l}\text { Observed No of } \\
\text { cases }\end{array}$ & $\begin{array}{l}\text { Relative risk with } 95 \% \text { confidence } \\
\text { interval }\end{array}$ & \multicolumn{3}{|c|}{ Relative risk $1961-6,1967-73,1974-9$} \\
\hline $\begin{array}{l}\text { Land/animal husbandry } \\
\text { Horticulture } \\
\text { Other agricultural occupations } \\
\text { Silviculture } \\
\text { Timber cutting } \\
\text { Other forestry occupations } \\
\text { Total study cohort }\end{array}$ & $\begin{array}{r}242 \\
10 \\
22 \\
15 \\
61 \\
5 \\
355\end{array}$ & $\begin{array}{l}1.02(0.88,1 \cdot 18) \\
0.99(0.48,1.82) \\
1.74(1.08,2 \cdot 61) \\
2 \cdot 26(1.25,3.69) \\
1.05(0.80,1 \cdot 35) \\
0.81(0.26,1.90) \ddagger\end{array}$ & $\begin{array}{l}0.92 \\
0.87 \\
1.25 \\
0.52 \\
0.97\end{array}$ & $\begin{array}{l}0.99 \\
1.04 \\
0.80 \\
2.25 \\
1.27\end{array}$ & $\begin{array}{l}1.17 \\
1.07 \\
3.53^{*} \\
3.85 \dagger \\
0.84\end{array}$ \\
\hline
\end{tabular}

*Test of trend $\chi^{2}(1)=5 \cdot 23$.

†Test of trend $\chi^{2}(1)=4 \cdot 97$.

$\ddagger$ Number of cases in the subcohort was too small to permit division into different periods.

was to seek clues to the cause of the disease.

The reviews of the 15 cases from the silviculture subcohort showed that eight had had posts in management or administration. All five fur farming workers were found to have worked with minks. One had also worked with fox breeding and one had been a railtrack worker. All four workers with other animal care had been engaged in poultry farming. The 12 cases in other relevant occupations had miscellaneous occupations such as cemetery worker, gardener in the parks of the town, landscape gardener, or bee-keeper.

\section{Discussion}

In another study from Sweden Hardell et al reported that exposure to phenoxy acids or chlorophenols may be a causal factor in malignant lymphoma. ${ }^{1}$ The occupational groups in Sweden with greatest exposure, both active and passive, to phenoxy acids are agricultural and forestry workers. In the present study, covering the period 1961-79, no increased risk of NHL could be found in such workers. Nor was any time related trend in RR for NHL found, although use of phenoxy acids has increased since the late 1940s.

A statistically significant increased relative risk of HD was found among men engaged in silviculture and there was also an increasing time related trend in

Table 4 Observed number of cases of Hodgkin's disease in 1961-79, relative risks, and 95\% confidence intervals for the total period in subgroups of "other agricultural occupations"

\begin{tabular}{|c|c|c|}
\hline & $\begin{array}{l}\text { Observed } \\
\text { No of } \\
\text { cases }\end{array}$ & $\begin{array}{l}\text { Relative risk } \\
\text { with } 95 \% \\
\text { confidence interval }\end{array}$ \\
\hline Reindeer husbandry & 0 & \\
\hline Fur farming & 5 & $4.45(1.41,10.15)$ \\
\hline \multicolumn{3}{|l|}{ Other animal care } \\
\hline (not livestock) & 4 & $2 \cdot 92(0 \cdot 79,7 \cdot 41)$ \\
\hline Veterinary work & 1 & \\
\hline Other relevant occupations & 12 & $1.41(0 \cdot 72,2 \cdot 46)$ \\
\hline Other agriculture & 22 & $1.74(1.08 .2 \cdot 61)$ \\
\hline
\end{tabular}

RR. Most of the men with HD in the silviculture cohort were in administrative positions. Some of them presumably had worked for many years in forestry, with corresponding exposure to phenoxy acids, whereas others may have come more or less direct from university and therefore had less exposure. In fur farming phenoxy acids presumably were not occupationally used and therefore the exposure probably was less than in other subcohorts in the study. Two of the fur farming men lived close together in the same village.

Our study differs structurally from the earlier Swedish investigation, ${ }^{1}$ which was a case-control study. A case-control study relies heavily on recall of distant events, with information sometimes provided by relatives of dead subjects and therefore some risk of uncertainty in the assessment of results. Our study was based on cohorts with presumed occupational exposure to phenoxy acids. One advantage of using CER and PH 60 was that data could be obtained concerning large numbers of people over long periods. A major disadvantage, as in many other register based studies, was the lack of individual data on occupational exposure. We have information only on the proportion of the workers in the studied cohort who have been exposed to phenoxy acids. The differences between the Hardell study and register based follow up studies have been discussed in a study on the risk of soft tissue sarcoma in the present cohorts. ${ }^{32}$

The possible loss of sensitivity in the present study due to definition of the cohorts on the employment status in a single year may be regarded as small. Of all the men aged 25-64 and employed in agriculture, forestry, or fishing in 1960 , only $13 \%$ were not in corresponding occupations in $1950 .^{33}$ Of the men employed in other economic activities in 1960, $8 \%$ had been employed in agriculture or forestry in $1950 .^{33}$

One explanation ior the abstince of increased risk of malignant lymphoma, particularly NHL, in the 
studied agricultural and forestry workers could have been underdiagnosis. Agricultural workers are known to use the health services less than do other occupational groups. ${ }^{34}$ Some types of tumour consequently will be less likely to be detected and notified to the cancer register. Moreover, Swedish agricultural workers were shown to have a decreased risk of cancer in general. ${ }^{24}$ Factors that may contribute to this decreased risk include lower consumption of tobacco and alcohol, a different diet, good general health, and more than average physical activity. The importance of such factors for the development of malignant lymphoma is not clear. To reduce healthy worker effect, the study cohort was compared with all men gainfully employed in economic activities other than agriculture or forestry rather than with the total male adult population.

The diagnostic criteria for various tumours are constantly being revised. One result may be that for certain tumours appreciable time related differences in incidence may seem to arise. Concerning malignant lymphoma, some cases formerly registered as HD may now be classified as NHL. The age standardised incidence of NHL showed a time related increase both in the study cohort and in the reference cohort. HD, by contrast, showed a decreasing incidence in the reference cohort, concomitant with no change in the study cohort. A time lag in the diagnostic revision in rural hospitals might explain the rising trend shown by HD in the study cohort.

In Vietnam veterans claiming exposure to Agent Orange the incidence of malignant lymphoma was found to be higher than the average among American men. ${ }^{2}$ Support for the earlier Swedish findings ${ }^{1}$ has also been provided by a British study of workers in a plant making pentachlorophenol, with two cases of NHL of the scalp, whereas the expected figure was $0 \cdot 28 .{ }^{3} \mathrm{~A}$ review of five patients with NHL of the skin in Sweden showed that four of them had been exposed to phenoxy acids. ${ }^{4} \mathrm{~A}$ case-control study in Kansas showed an excess risk for NHL that increased significantly with number of days of herbicide exposure a year and latency. ${ }^{5}$ A cohort study in Denmark of employees at a plant manufacturing phenoxy herbicides showed a non-significant excess risk of malignant lymphoma ( 7 observed cases, 5.37 expected) after exposure to phenoxy herbicides. ${ }^{6}$

Excess incidence of HD has been found in woodworkers who could have been exposed to pentacholorophenol. ${ }^{35-39}$ Risk of HD or NHL, or both, was found to be increased also in farmers. ${ }^{40-42}$ In a study of myeloproliferative and lymphoproliferative disorders in Tasmania during 1972-80 the RR for NHL among farmers and farm labourers was 1.80 $(p<0.05)$. For HD the RR was 2.33 , but the excess was not statistically significant. ${ }^{40}$ In a study on farm- ing and mortality in California 1959-61 the SMR was 1.09 for HD and 0.76 for NHL among farm residents. ${ }^{41}$ In a case-control study of NHL in Wisconsin in 1968-76 the odds ratio for farming occupations was 1.22 .42 The association with such work was greater among decedents younger than 65 . Analyses of death certificates for white male Iowans in 1964-78 resulted in an odds ratio of 1.26 for NHL among farmers. ${ }^{43} \mathrm{~A}$ study in New Zealand found that agricultural workers had an increased risk of NHL. ${ }^{44}$

Handling of domestic animals, especially rabbits, has been proposed as an aetiological factor in $\mathrm{HD},{ }^{45}$ as were poultry viruses, though with little support from human studies. ${ }^{46}$ Veterinarians have been shown to be at increased risk of HD, and also of leukaemia, NHL, and myeloma. ${ }^{47}$ The finding in our study of an association between HD and fur farming and poultry breeders, respectively, will be investigated in an extended study.

The study was supported by grants from the King V Jubilee Fund (82:533), the Stockholm Cancer Society (83:91), the Swedish Farmers' Safety and Preventive Association, the Swedish Medical Research Council (B84-27X-6885-01A), and the Swedish Product Control Board (14-83/84).

\section{References}

1 Hardell L, Eriksson M, Lenner P, Lundgren E. Malignant lymphoma and exposure to chemicals, especially organic solvents, chlorophenols and phenoxy acids. A case-control study. $\mathrm{Br} J$ Cancer 1981;43:169-76.

2 Young AL, Flicker MR, Kang HK, Shepard BM. Health surveillance of Vietnam veterans claiming Agent Orange exposure. In: Chlorinated dioxins and dibenzofurans in the total environmentII. (Symposium proceedings.) American Chemical Society (in press).

3 Bishop CM, Jones AH. Non-Hodgkin's lymphoma of the scalp in workers exposed to dioxins. Lancet 1981;ii:369.

4 Olsson H, Brandt L. Non-Hodgkin's lymphoma of the skin and occupational exposure to herbicides. Lancet 1981;ii:579.

5 Hoar SK, Blair A, Holmes FF, et al. Agricultural herbicide use and risk of lymphoma and soft-tissue sarcoma. JAMA 1986;256:1141-7.

6 Lynge E. A follow-up study of cancer incidence among workers in manufacture of phenoxy herbicides in Denmark. $\mathrm{Br} \mathrm{J}$ Cancer 1985;52:259-70.

7 Riihimäki V, Asp S, Pukkala E, Hernberg S. Mortality and cancer morbidity among chlorinated phenoxyacid applicators in Finland. Chemosphere 1983;12:779-84.

8 Milham S. Herbicides, occupation, and cancer. Lancet 1982;i:1464-5.

9 Blondell JM. Cancer mortality and pesticide use among rural farm counties in the United States, 1950-1969. Am J Epidemiol 1979;110:356.

10 Gallagher RP, Threlfall WJ. Cancer and occupational exposure to chlorophenols. Lancet 1984;ii:48.

11 Axelson O. Sundell L, Andersson K, Edling C, Kling H. Herbicide exposure and tumour mortality. Scand $J$ Work Environ Health 1980;6:73-9.

12 Thiess AM, Frentzel-Beyme R, Link R. Mortality study of persons exposed to dioxin in a trichlorophenol-process accident 
that occurred in the BASF AG on November 17, 1953. Am J Ind Med 1982;3:179-89.

13 Zack JA, Suskind R. The mortality experience of workers exposed to tetrachlorodibenzodioxin in a trichlorophenol process accident. J Occup Med 1980;22:11-4.

14 Cook RR, Townsend JO, Ott MG, Silverstein LG. Mortality experience of employees exposed to 2,3,7,8-tetrachlorodibenzo-p-dioxin (TCDD). J Occup Med 1980;22:530-2.

15 Suskind $R$. Long-term health effects of exposure to 2,4,5-T and/or its contaminants. Chemosphere 1983;12:769.

16 Wang $\mathrm{HH}$, MacMahon B. Mortality of pesticide applicators. $J$ Occup Med 1979;21:741-4.

17 Blair A, Grauman DJ, Lubin JH, Fraumeni JF. Lung cancer and other causes of death among licensed pesticide applicators. JNCI 1983;71:31-7.

18 Barthel E. Cancer risk in pesticide exposed agricultural workers. Arch Geschwulstforsch 1981;51:579-85. (In German.)

19 Hogstedt C, Westerlund B. Cohort study of mortality among forestry workers with and without exposure for phenoxy herbicides. Läkartidningen 1980;77:1828-30. (In Swedish.)

20 United States Air Force. Project ranch hand II. An epidemiologic investigation of health effects in air force personnel following exposure to herbicides. Texas: USAF, 1983.

21 May G. Tetrachlorodibenzodioxin: a survey of subjects ten years after exposure. $\mathrm{Br} J$ Ind Med 1982;39:128-35.

22 Ott MG, Holder BB, Olson RD. A mortality analysis of employees engaged in the manufacture of 2,4,5-trichlorophenoxyacetic acid. J Occup Med 1980;22:47-50.

23 Zack JA, Gaffey WR. A mortality study of workers employed at the Monsanto company plant in Nitro, West Virginia. Environ Sci Res 1983;51:575-91.

24 Wiklund K. Swedish agricultural workers. A group with a decreased risk of cancer. Cancer 1983;51:566-8.

25 Bäckström J. The phenoxy acid problem in Sweden. In: Chlorinated phenoxy acids and their dioxins. Ecological Bulletin 1978;27:108-21.

26 National Central Bureau of Statistics. The control study made in connection with the 1960 census of population. Statistical reports B. Stockholm: NCBS, 1964:16.

27 World Health Organisation. International classification of diseases, injuries and causes of death (ICD), 1955 revision. Geneva: WHO, 1957.

28 Wiklund K, Einhorn J, Wennström G, Rapaport E. A Swedish cancer-environment register available for research. Scand $J$ Work Environ Health 1981;7:64-7.

29 Kleinbaum DG, Kupper LL, Morgenstern H. Epidemiologic research. Belmont, California: Lifetime Learning Publications,
1982.

30 Breslow NE. Elementary methods of cohort analysis. Int J Epidemiol 1984;13:112-5.

31 Breslow NE, Day NE. Statistical methods in cancer research. Lyon: International Agency for Research on Cancer, 1980. (Sci publ No 32.)

32 Wiklund K, Holm L-E. Soft-tissue sarcoma risk in Swedish agricultural and forestry workers. JNCI 1986;86:229-34.

33 Central Bureau of Statistics. Census of the population in 1960, XI sample surveys: families, income, internal migration and change of industry. Stockholm: CBS, 1965.

34 Den jämlika sjukvården. Hälso- och sjukvård inför 90-talet. Stockholm: Allmänna förlaget, 1984. (SOU 1984:41.)

35 Grufferman S, Duong T, Cole P. Occupation and Hodgkin's disease. $J N C I$ 1976;57:1193-5.

36 Greene MH, Brinton LA, Fraumeni JF, D'Amico R. Familial and sporadic Hodgkin's disease associated with occupational wood exposure. Lancet 1978;ii:626-7.

37 Milham S, Hesser JE. Hodgkin's disease in woodworkers. Lancet 1967;ii:136-7.

38 Acheson ED. Hodgkin's disease in woodworkers. Lancet 1967;ii:988-9.

39 Petersen GR, Milham S. Hodgkin's disease mortality and occupational exposure to wood. JNCI 1974;53:957-8.

40 Giles GG, Lickiss JN, Baikie MJ, Lowenthal RM, Panton J. Myeloproliferative and lymphoproliferative disorders in Tasmania, 1972-80: occupational and familial aspects. JNCI 1984;72:1233-40.

41 Fasal E, Jackson EW, Klauber MR. Leukemia and lymphoma mortality and farm residence. Am J Epidemiol 1968;87:267-74.

' 42 Cantor KP. Farming and mortality from non-Hodgkin's lymphoma: a case-control study. Int J Cancer 1982;22:239-47.

43 Burmeister LF, Everett GD, Van Lier SF, Isacson P. Selected cancer mortality and farm practices in Iowa. Am J Epidemiol 1983;118:72-7.

44 Pearce NE, Smith AH, Fisher DO. Malignant lymphoma and multiple myeloma linked with agricultural occupations in a New Zealand cancer registry study. Am J Epidemiol 1985;121:225-37.

45 Dörken M. Eine Epidemiologische Studie über $140 \mathrm{Kinder-}$ Stadt/Land-Relation. Berufe der Eltern. Kontakte mit Haustieren. Arch Geschwulstforsch 1975;45:283-98.

46 Priester WA, Mason TJ. Human cancer mortality in relation to poultry population, by county, in 10 southeastern states. $\mathrm{JNCI}$ 1974;53:45-9.

47 Blair A, Hayes HM. Mortality patterns among US veterinarians, 1947-1977: an expanded study. Int J Epidemiol 1982;11:391-7. 